\title{
Review of Literature and Case Report for a Two Year Old Child with Dislodged PDA Device into External Iliac Artery
}

\author{
Tauqeer Anjum Mir ${ }^{1}$, Vishwas Sathe ${ }^{2}$, Olvyna D'souza ${ }^{3}$, Deepika Sareen ${ }^{4}$, \\ Rohan Roshan Nayak ${ }^{5}$ \\ ${ }^{l}$ Department of Anaesthesia MGM Medical College \& Hospital Kamothe, Navi Mumbai-410209, \\ Maharashtra, India \\ ${ }^{2}$ Department of Anaesthesia MGM Medical College \& Hospital Kamothe, Navi Mumbai-410209, \\ Maharashtra, India \\ ${ }^{3}$ Department of Anaesthesia MGM Medical College \& Hospital Kamothe, Navi Mumbai-410209, \\ Maharashtra, India \\ ${ }^{4}$ Department of Anaesthesia MGM Medical College \& Hospital Kamothe, Navi Mumbai-410209, \\ Maharashtra, India \\ ${ }^{5}$ Department of Anaesthesia MGM Medical College \& Hospital Kamothe, Navi Mumbai-410209, \\ Maharashtra, India
}

\begin{abstract}
Patent ductus arteriosus (PDA) is a condition which is characterised by the failure of closure of the ductus arteriosus after birth.Early symptoms include increased work of breathing and poor weight gain in infancy. If left untreated, PDA may lead to congestive cardiac failure with progressing age.

We report a case wherein a three year old female child had been diagnosed with PDA and was referred to Cardiology for further management. She was planned for PDA device closure in Cath-Lab trans-cutaneously via femoral artery. The device, however, got dislodged into the external iliac artery on right side as detected by C-Arm image intensifier. Emergency team from CVTS had been called upon and exploration of the femoral sheath was done. The device was retrieved with peripheral pulsations being intact. The case was managed under general anesthesia. Patient was extubated on table and had got shifted thereafter to PICU.
\end{abstract}

Keywords: PDA (Patent Ductus Arteriosus), Hypotension, Arterial Line, Peripheral Pulsations, Anastomosis.

\section{Introduction}

The Ductus Arteriosus is a fetal blood vessel which closes immediately in the postnatal period. In a PDA, the vessel fails to close and remains patent which results in mixing of blood between the descending thoracic aorta and the left pulmonary artery. PDA is common in premature newborns and neonates with persistent respiratory problems such as hypoxia.

Although, the closure of small ducts ( $<2 \mathrm{~mm}$ using detachable coils) have shown satisfactory results, there is yet a higher incidence of residual shunt, hemolysis and embolization in larger ducts.[1] In 1998, Masura et al.[2] published the first series of cases of percutaneous closure of the arterial duct by using the Amplatzer device, which was specifically designed for medium to large ducts. Percutaneous closure of patent ductus arteriosus (PDA) using an Amplatzer Duct Occluder (ADO) rarely has any complications. However, technical difficulties may lead to severe complications. In this article, we report a case of PDA device dislodgement into right external iliac artery which was removed successfully via arteriotomy of the right femoral artery. Primary anastomosis of the proximal and distal ends of the said vessel was achieved with intact peripheral pulsations.

\section{Case Report}

A three-year-old girl, weighing 7kgs, was admitted under the Cardiology Department of our hospital as a case of a large PDA (5 -5.5 mm diameter, $2.2 \mathrm{~mm}$ length), determined by preoperative echocardiography. Rest of the baseline investigations were within normal limits. She was planned for the device closure of the defect under general anaesthesia. The patient was shifted to the Cath-Lab on April $26^{\text {th }}, 2016$ and the procedure had been undertaken. Connecting ECG electrodes, IBP and $\mathrm{SPO}_{2}$ probe, an intravenous line (24G) was secured. Induction of anaesthesia was carried out with intravenous Propofol $2 \mathrm{mg} \mathrm{kg}^{-1}$, Midazolam $0.05 \mathrm{mg} \mathrm{kg}^{-1}$ and fentanyl $1 \mu \mathrm{g} \mathrm{kg}^{-1}$. Tracheal intubation was done with $5.0 \mathrm{~mm}$ endotracheal tube post administration of inj. Atracurium $0.5 \mathrm{mg} / \mathrm{kg}$. Anaesthesia was being maintained with Oxygen, Nitrous oxide and Sevoflurane. The child was being initially ventilated with Jackson Ree's modification of Ayre's T-piece to later on CMV. The patient's blood pressure was $90 / 60 \mathrm{~mm} \mathrm{Hg}$ initially, heart rate $140 \mathrm{bpm}$.

The PDA was accessed transcutaneously via femoral artery. The occluder device, however, got dislodged during placement into descending thoracic aorta, then into the abdominal aorta and lastly into the 
external iliac artery on the right side, as detected by C-arm image intensifier. Several attempts were carried out to retrieve the device transcutaneously without success. Emergency team from CVTS was called upon instantaneously and exploration of the femoral sheath on right side was done. The device was finally retrieved via arteriotomy of the right femoral artery accessed via femoral sheath dissection. It was followed by primary vascular anastomosis of the proximal and the distal ends of the said vessel. The surgical challenge was to achieve distal pulsations for which complete haemostasis was done. Initially proximal pulsations had been felt whereas the distal were feeble. Re-exploration of the femoral sheath was carried out and the distal pulsations were confirmed. The incision was closed back in layers. The vitals of the patient especially the BP had been fluctuating post arteriotomy challenging the involved anaesthesiologists. Despite the challenges, the haemodynamic stability of the patient was being maintained and intraoperative heparin was also administered to reduce the risk of thromboembolism. Patient was catheterized towards the end of the procedure and was extubated on table. Later patient was shifted to PICU with the postoperative course being uneventful.

\section{Discussion}

Recent advances in the closure of PDA have overcome technical difficulties making interventional trans-catheter procedures simple, minimally invasive with shorter hospitalization, earlier recoveries, less mortality and morbidity rates [3]. Moreover, it also risks off the surgical burden and the operative scar. It was first described by Porstmann et al.[4] in 1967. Since then different devices have been devised and brought into the clinical practice. Gianturco and Cook detachable coils have been found to be quite safe and effective in the closure of small to moderate sized PDA's,[]] while ADO and Nit-occlud devices have been introducedfor moderate to large sized PDA's.[ㅁ]

However, there are some complications pertaining to these procedures including dislodgement of the device into aorta or pulmonary artery, residual shunt with or without hemolysis, endocarditis, thromboembolism, wirefracture or device disruption.[7] Major complication risk is almost $10 \%$ in some studies [8]. Device dislodgement, the most significant [9], constitutes complication rate of $1.4 \%$ in large series ${ }^{\mathbf{1 0}}$. Immediate surgical intervention is preferred to remove the migrated device, as it facilitates early retrieval of the device before further embolization in both haemodynamically stable and unstable cases.

In our case report, the device got dislodged initially into the descending thoracic aorta, then migrated into the abdominal aorta and finally into right sided external iliac artery. The cardio-thoracic surgeon had performed right femoral arteriotomy by opening the femoral sheath on right side and the device was removed under general anaesthesia. The two ends of the vessel had been primarily anastomosed to each other and the peripheral pulsations were intact. The girl was extubated and had later got shifted to PICU for further monitoring.

The anaesthetic challenge was the lengthening of the procedure due to dislodgement and maintainance of the vitals combating hypotension and hypothermia in a pediatric patient of $7 \mathrm{kgs}$ for about 9 hours. Anaesthesia was being maintained during the entire procedure with accurate volume replacement. Ultimately, after the retrieval of the dislodged device, the child was extubated on the table and shifted to PICU. The child recovered uneventfully and was discharged after 5 days and scheduled for a repeat procedure after three months.

\section{Conclusion}

Percutaneous closure of ductus arteriosus is a minimally invasive intervention which is safe, quick and effective alternative to surgery. However, due to unfavorable duct anatomy, mismatch occurs between implanted occluder size and anatomical PDA diameters leading to PDA under estimation and subsequent complications. Under such circumstances open surgical exploration offers an important rescue shift and necessitates the availability of cardiac and vascular surgery team with anaesthesia cover during the procedure.

Acknowledgement

1. Department of Cardio-vascular and Thoracic Surgery, MGM Medical College Navi Mumbai

\section{Department of Cardiology, MGM Medical College Navi Mumbai}

\section{References}

[1]. Boehm W, Emmel M, Sreeram N. The Amplatzer duct occluder for PDA closure: indications, technique of implantation and clinical outcome. Images PaediatrCardiol 2007;9:16-26.

[2]. Masura J, Walsh KP, Thanopoulous B, Chan C, Bass J, Goussous Y, et al. Catheter closure of moderate- to largesized patent ductus arteriosus using the new Amplatzer duct occluder: immediate and short-term results. J Am CollCardiol 1998;31:878-82.

[3]. Behjati-Ardakani M, Behjati-Ardakani MA, Hosseini SH, Noori N. Long-term results of transcatheter closure of patent ductus arteriosus in infants using amplatzer duct occluder. Iran J Pediatr 2013;23:411-16.

[4]. Porstmann W, Wierny L, Warnke H. Closure of persistent ductus arteriosus without thoracotomy. Ger Med Mon 1967;12:259-61. 
[5]. Galal MO. Advantages and disadvantages of coils for transcatheter closure of patent ductus arteriosus. J IntervCardiol 2003;16:15763.

[6]. Peirone A, Diaz J, Contreras A, Banille E, Cabrera M, Spillmann A, et al. Percutaneous closure of the patent ductus arteriosus using the Nit-Occlud PDA-R (reverse) device: initial experience reporting immediate and shortterm results. J Invasive Cardiol 2011;23:513-6.

[7]. Faella HJ, Hijazi ZM. Closure of the patent ductus arteriosus with the amplatzer PDA device: immediate results of the international clinical trial. Catheter CardiovascInterv 2000;51:50-4.

[8]. Parra-Bravo R, Cruz-Ramírez A, Rebolledo-Pineda V, Robles-Cervantes J, Chávez-Fernández A, Beirana-Palencia L, et al. Transcatheter closure of patent ductus arteriosus using the amplatzer duct occluder in infants under 1 year of age. Rev EspCardiol 2009;62:867-74.

[9]. Amanullah MM, Siddiqui MT, Khan MZ, Atiq MA. Surgical rescue of embolizedamplatzer devices. J Card Surg 2011;26:254-58.

[10]. Bilkis AA, Alwi M, Hasri S, et al. The Amplatzer duct occluder: Experience in 209 patients. J Am CollCardiol. 2001;37:258-261

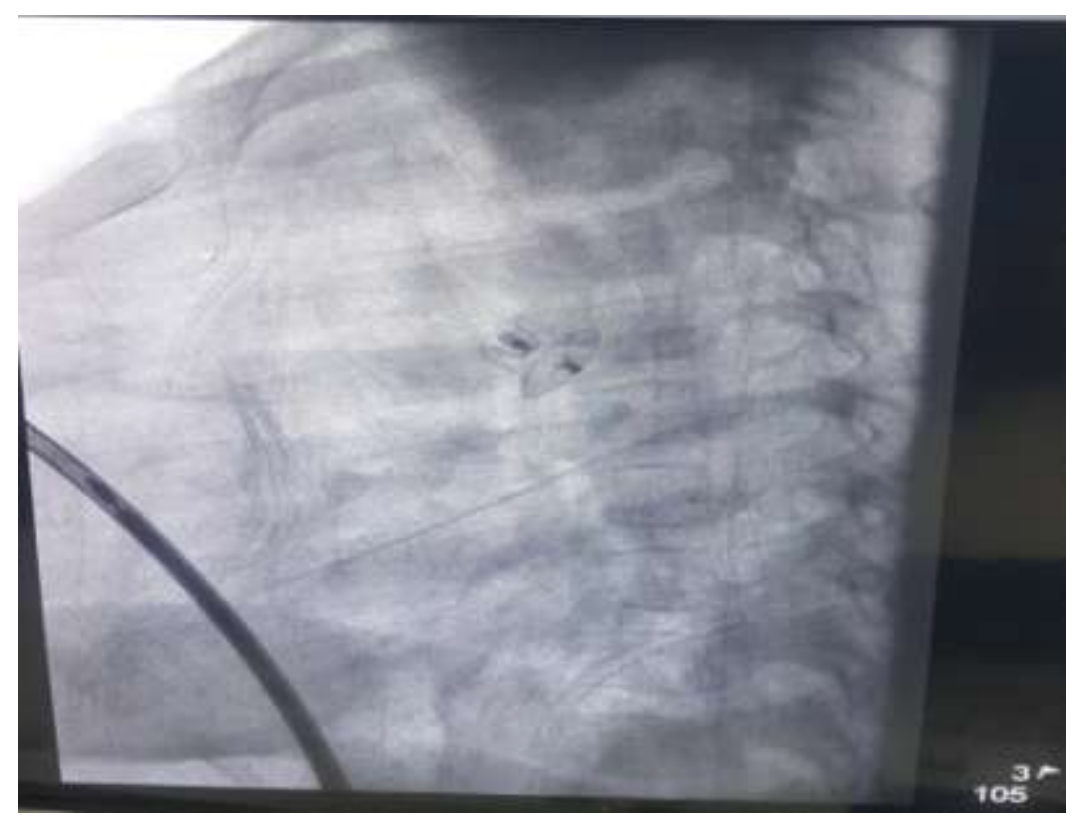

Pictured above PDA Device migrating downwards towards descending aorta 